\title{
INFLUÊNCIA DA CULTURA NA EDUCAÇÃO
}

\section{ENSAIO TEÓRICO}

SILVA, Marcos Antonio da Conceição ${ }^{1}$

SILVA, Marcos Antonio da Conceição. Influência da cultura na educação. Revista Científica Multidisciplinar Núcleo do Conhecimento. Ano 04, Ed. 10, Vol. 11, pp. 114128. Outubro de 2019. ISSN: 2448-0959, Link de acesso: https://www.nucleodoconhecimento.com.br/educacao/cultura-na-educacao

\section{RESUMO}

A cultura se define como um elemento dinâmico na existência humana, pois não existe indivíduo que não tenha sua própria cultura, onde cada um a cria e difunde. Este estudo visa buscar em sua abordagem entender qual a influência da cultura na educação, pois a fala sobre educação deve fundamentar a base da sua discussão em sua responsabilidade social que está centrada em formar um cidadão com competência para desenvolver-se em suas atividades cotidianas prezando os valores essenciais de sociabilidade entre indivíduos. Trata-se de um estudo de cunho bibliográfico, preocupado em identificar as considerações dos autores acerca da temática abordada.

Palavras-chave: Influência, cultura, educação.

\section{INTRODUÇÃO}

As diversas abordagens do termo cultura, muitas vezes direciona o pensamento à música, literatura, artes, ou uma infinidade de habilidades desenvolvidas durante o percurso da existência do homem; entretanto, sua perspectiva é muito mais ampla,

1 Doutorando em Educação; Mestrado em Educação; Pós-graduação em Psicopedagogia e Docência no Ensino Superior; Graduado em Gerenciamento de Redes, Informática, Matemática e Pedagogia. 
considerando-se que a cultura pode ser concebida como tudo que o homem produz (OLIVEIRA, 2011). De acordo com Lopes, Mendes e Faria (2005, p. 13), sua definição se refere às "teias de significados" construídas ao longo da existência humana; tudo que a ele faz referência e que ele adquire e significa durante sua existência partindo sempre das relações sociais.

Outrossim, quando se conceitua o termo cultura, compreende-se sua expressiva importância nas relações histórico-sociais, podendo-se inclusive afirmar que sua influência de massa acaba permitindo a preservação de grupos sociais, detendo características que se manifestam no cotidiano, no comportamento social e nas produções físicas e imateriais.

Como exemplo evidente disso, o que é escrito ou verbalizado no mesmo instante e os últimos pensamentos elaborados refletem toda a história vivenciada pelo indivíduo com seu percurso de vida e valores arraigados. Estes acervos originados na história, na vivência de cada pessoa, se traduzem nas suas experiências adquiridas.

O papel social de um indivíduo ou a atividade por ele desempenhada, são peculiaridades transmitidas no próprio ambiente familiar ou pelo grupo social ao qual pertence, e esta é a forma que a sociedade preserva e mantém seus valores. $O$ "modo de produção capitalista" (GUARESCHI, 2008, p. 33), define duas formas de conservação da sociedade, primeiro através da genética que perpetua as características propriamente humanas ou por meio dos processos sociais e culturais, resultantes das interações sociais granjeada na família, na escola, no trabalho, no mercado, na praça, isto traduz o processo cultural do ser humano.

Nesses processos estão incorporados diversas dinâmicas e posturas, todos os aprendizados adquiridos formal ou informalmente, sejam os referentes a crenças, hábitos, idioma, alimentação etc. Todos estes fatores representam as manifestações culturais, sendo muitos destes originados nas interações familiares. 
Refletir sobre os processos culturais partem do universo infantil e se estende por todo o percurso de aprendizagens do sujeito, pois a estrutura cultural herdada e construída na sua família tem o poder de auxiliá-la na elaboração de novos saberes.

Dessa forma, este estudo visa promover a ampliação do conhecimento sobre a influência da cultura na educação e será desenvolvido por meio da pesquisa bibliográfica a partir de posicionamentos de autores, por meio de busca em livros, artigos, dissertações de mestrado, para maior enriquecimento da temática abordada com metodologia baseada em revisão bibliográfica.

\section{SIGNIFICADOS CULTURA \& EDUCAÇÃO}

Ao se abordar a temática "cultura", esta faz referência ao que o homem produz, podendo esta ser reproduzida como herança de pais para filhos; não são exatamente produto espontâneo, mas resultam das ações humanas. Em razão disto, a cultura também pode ser ensinada e aprendida pelas gerações que se seguem, sendo implícito que estas estão encarregadas da sua preservação.

Quando se refere à sua função de transmitir valores culturais da educação, seu significado se traduz como uma riqueza de conhecimentos e competências, institucionais, integradas de valores e de símbolos, compostos durante diversas gerações e com características de uma comunidade humana peculiar, conceituada de forma mais ou menos ampla e exclusiva, resultando em uma obra e um bem coletivo (FORQUIN, 1997).

Conforme afirma Oliveira (2011), existe uma cultura em cada povo, onde cada grupo social constrói e recebe outras influências culturais, considerando que desde o seu nascimento, a pessoa é influenciada pelo ambiente social à qual está incorporada. Assim, entenda-se que não pode existir uma pessoa desprovida de cultura.

Já Freire (2011a, p. 30) explana que a "cultura se define a partir de tudo que o homem cria". Assim, conforme explica o antropólogo Kluckhohn (1963, apud OLIVEIRA, 2011, p. 135) esta se traduz como "toda a vida de um povo, como uma herança social 
adquirida do próprio grupo ao qual é pertencente, ou ainda pode ser entendida como parte do próprio ambiente criado".

Neste sentido, a cultura, segundo explica Severino (2010, p. 81) significa "uma conjunção de objetos que resultam das atividades produtivas, sociais e simbólicas dos homens". Lopes, Mendes e Faria (2005, p. 13), fazem uma referência de Vygotsky, explanando que:

Observando conceitos e definições, se pode compreender que a cultura se denomina à partir de tudo que circunda o homem, tudo que é visto, ouvido, aprendido, e conhecido, na sua interação social durante toda sua existência, tudo que se refere ao homem em sociedade e, especialmente, se refere a toda a sua produção: bens materiais e bens simbólicos.

Distintamente ao mundo da natureza, o que foi produzido veio pelas mãos do homem, como fruto de sua imaginação e criação (VYGOSTSKY, apud LOPES et al. (Orgs.), 2005). Assim, quando se trata do termo cultura, seu significado faz referência a tudo que foi produzido pelas mãos humanas e que foi preservado como bem social, assim, ela tem relação dom os valores dos grupos sociais, experienciado pelos indivíduos, mas se define como bens e valores sociais.

Já a educação, conforme descrição dos índios, é um segmento que integra a cultura; reproduzindo e cuidando dos valores a ela intrínsecos, consequentemente, não obstante que a educação ignore que está inserida em uma realidade onde sua função é a organização e sistematização da estrutura social, onde é participante.

Entenda-se que, como a educação é um fator que constitui e é constitutivo a partir da cultura, e esta deve estar no ponto para ser capaz de auxiliar na promoção da formação necessária para a integração da sociedade, visando conjuntamente e em prol desta, as ferramentas indispensáveis à aprendizagem dos conhecimentos com real significado social.

Dessa forma, Paulo Freire (1921-1997) atenta para o cunho dialógico da educação, pressupondo a comunicação entre as partes, para que esta seja estabelecida num mesmo nível, isto é, dentro da mesma realidade. O consagrado autor aponta ainda 
que, todo diálogo demanda a existência de um conteúdo para dialogar e, por esta razão, determina um tipo de planejamento destinado a orientar este diálogo, devendo ser abordado, conforme explana Freire (2011a, p.108):

(...) o conceito antropológico de cultura, onde existe a distinção entre os dois mundos: o da natureza e o da cultura. A função ativa do homem em e com sua realidade. Assim, a perspectiva de mediação que possui a natureza para as relações e comunicação entre os homens e a cultura é concebida como o que o homem é capaz de acrescentar a que ele não criou e é resultado do seu trabalho, da sua capacidade de criar e recriar.

Neste sentido, a cultura é a vertente transcendental resultante de suas relações, como uma dimensão humanista, como aquisição sistemática de tudo que o homem experimenta. Parte do que é incorporado, sendo crítica e criadora, pois não resulta de uma sobreposição de algo que foi doado ou prescrito. Assim, a democratização da cultura expande as dimensões da democratização fundamental, onde a aprendizagem da escrita e da leitura funcionam como a solução para que o analfabeto inicie sua incorporação no universo da comunicação escrita, ou seja, o homem, no mundo e como mundo, sua função de sujeito e não de simples e permanente objeto (FREIRE, 2017d).

Dessa forma, nesta perspectiva de entendimento, a educação abrange todas as dimensões humanas, assim, de acordo com Morin (2014, p. 11):

A função do ensino se baseia na transmissão, não do simples saber, mas de uma cultura que possibilite o entendimento acerca da nossa condição que nos auxilie a viver e seja, ao mesmo tempo, favorável a uma forma de pensar mais aberta e livre.

Por este ângulo, a educação abrange o homem como uma agregação biossocial, que se constitui e se transfigura a partir dessa relação dialógica e, apenas desta forma, seu desenvolvimento é possível e ocorre e uma relação dialética com a sociedade, ou seja, o homem forma e é formado pelo ambiente que o cerca (VYGOTSKY, 2007).

Como exemplo desta perspectiva, pode-se observar o reflexo na própria Teoria da Zona de Desenvolvimento Proximal de Vygotsky, expressando claramente o desenvolvimento das capacidades infantis sendo consequentes ao processo da 
interação social, definindo como o distanciamento entre o nível de desenvolvimento real, que normalmente se determina por meio da resolução que independe das dificuldades, e do grau de desenvolvimento potencial, estando orientado por uma pessoa adulta ou com parceiros mais capacitados (VYGOTSKY, 2007).

Dessa forma, é imperiosa a mediação instrumental, isto é, a utilização de recursos culturais para a intervencionar a criança no meio, à proporção que ela toma deste, os elementos necessários para a constituição e amadurecimento da dinâmica que relaciona linguagem e pensamento, imprescindíveis ao seu desenvolvimento sócio histórico (VYGOTSKY, 2007).

A íntima relação entre educação e cultura na formação do homem como ser cidadão, salienta a natureza fundamental das ações que integram as demonstrações artísticas e intelectuais nas práticas pedagógicas dos ensinos formais e informais. Entretanto, cabe corrigir a fragmentação entre as concepções e planejamentos das políticas que se referem às duas esferas como centro de articulações dos distintos âmbitos da administração pública.

Em outro aspecto, é premente que se reconheça que as dificuldades de acessos à educação e à cultura produzem impactos concomitantes. A exemplo disto, estão os lapsos na formação artístico-cultural dos alunos no Brasil, que desta forma deixam de integrar um grupo social antenado e com críticas pertinentes sobre a recepção e produção de manifestações simbólicas.

As prioridades dos desafios voltados a uma política cultural vinculada a de educação abrangem a formação de professores, bens culturais disponíveis a docentes e discentes, as trocas de informações e aplicação de competências entre as duas esferas, os reconhecimentos sobre os conhecimentos tradicionais, a partilha de projetos e recursos, o aperfeiçoamento do ensino das artes em escolas, bem como as transformações que estas instituições sofrerão ao se constituírem centros de convivências e experiências culturais. 
A prática do estudo, tem caráter social, não somente individual, ocorrendo independe de que os sujeitos estejam conscientes ou não. Assim, intrinsecamente, o ato de estudar, como um ato de curiosidade do indivíduo frente ao mundo, se traduz como uma forma de expressar e estar dos indivíduos, como pessoas sociais, históricas, construtoras, transformadoras, que não somente sabem, mas tem consciência de que sabem (FREIRE, 2011a).

\section{CULTURA: A PRIMEIRA ETAPA DA EDUCAÇÃO}

Durante a vida humana, existe uma coisa muito importante na educação que é a fase que compreende do desde que nasce até sua puberdade. Esta é uma fase essencial para o desenvolvimento do ser humano, onde a criança começa a desenvolver sua percepção à sua volta.

É na fase infantil que se irrompem dimensões privilegiadas nas aprendizagens significativas da criança, e sua evolução está vinculada à socialização e sua formação histórico-cultural presumem afetos, valores, desenvolvimentos motores, cognitivos, psicomotores. Estas proporções, porém, nunca devem ser apartadas ou fragmentadas na elaboração da cientificidade, pois são na realidade os fundamentos do conhecimento humano (PIMENTEL, 2008).

Dessa forma, os infantes adentram o espaço escolar levando consigo sua história, seu percurso na vida, que traduzem seus conhecimentos prévios. Estes saberes produzidos nos cotidianos estimulam a curiosidade de entender o que acarreta na ampliação dos seus saberes, onde suas histórias de vida funcionam como motores propulsores que norteiam a vida das pessoas e é aí que repousa a expressiva importância das contribuições da cultura para o percurso acadêmico dos alunos.

A partir deste fundamento se pode afirmar que os valores oriundos dos universos familiares podem ser concebidos como a base de novas aprendizagens. Conclui-se que o ambiente escolar necessita, realmente, estimular pensamentos inovadores auxiliando a criança a se tornar estudiosa; entretanto, apesar de passado algum 
tempo desde a proposta de um ambiente direcionado para o aluno, ainda não se conquistou a educação almejada (FREIRE, 2011b).

Considerando estes desafios, cabe questionar do que realmente a cultura é capaz, porém se deve problematizar cada contexto, buscando direção para solucionar cada um deles; ou se ela é intrínseca a cada indivíduo, se seus saberes são únicos, mas aí está sua relevância cultural, pois ela é a base e o começo para a evolução de cada um.

Todavia, se questiona a razão pela qual a cultura popular não é admitida no denominado grupo dominante e constata que no ambiente escolar nem sempre a cultura é bem recebida, pois sua metodologia retrata os grupos dominantes. Por conseguinte, o processo de ensino-aprendizagem ainda não consegue suprir as expectativas do povo, e, por conseguinte, ainda não retrata uma libertação (GIROUX, 2006).

Segundo a constatação de Freire (2011c, p. 30), "o homem está com o mundo e incorporado nele, se somente permanecesse existiria transcendência nem teria finalidade em si mesmo". Este indivíduo representa a construção de elementos da sua imaginação que irão se tornar realidade no início das experiências vivenciadas socialmente. Outrossim, é atribuída subjetividade partindo da consciência do objeto (SEVERINO, 2010), ressaltado em uma representação conhecida como a rede e o peixe que segundo relata ALVES (2009, p. 17):

O mundo de cada um se restringe aquilo que pode expressar, a linguagem é ontológica e a mesma coisa ocorre se a abordagem for referente a cor, cheiro, sentimento, poesias, amor, músicas e felicidade, pois não existem redes que as possam reter.

Pode-se considerar o que relata Severino (2010, p. 80) quando afirma que: "a subjetividade é elemento contemporâneo à origem do homem, surgindo como estratégia vivencial e instrumental para as ações". Pode-se afirmar, então, que, sob a perspectiva antropológica, a consciência surge intrínseca e intimamente vinculada ao processo da ação. 
Efetivamente, o simbolismo requer da mente do indivíduo ações subjetivas de ampla complexidade para a concretização do imaginário e do íntimo do indivíduo (SEVERINO, 2010). Por esta razão, Kuenzer (2002, p. 32) afirma que: "as linguagens, as narrativas, etc. não somente retratam ou relatam acerca das coisas, mas as instituem criando sua realidade" e com esta afirmativa, pode-se tomar o entendimento de Freire (2011c, p. 28), quando diz que "o homem deve estar subordinado à sua própria educação", com a capacidade de mudar suas realidades partindo das relações históricas, onde a cultura local proporcione o fundamento que tanto impele o pósmodernismo.

Nesta perspectiva, Kerschensteiner apud Bamberger (2002, p. 33), afirma que "é por meio dos bens culturais que a pessoa busca ajustar-se à estrutura social". Dessa forma, entende-se que a criança, enquanto um ser que pensa, capaz de apreender conhecimento, está visceralmente vinculada na estruturação de um mundo mais assertivo; isto ocorre se a sociedade, quando transmitir os valores relacionados ao contexto escolar, considerar que cada pessoa tem o poder transformador do ambiente em que vive.

\section{A CONSTRUÇÃO DA IDENTIDADE SOCIAL}

Neste contexto em especial, o papel cultural no processo ensino-aprendizagem pode ser de direcionador da sua posição frente ao mundo e desenvolvendo sua real aprendizagem com seus conhecimentos preambulares, pois tem a finalidade de estruturar uma educação ampla, fundamentado em construir a identidade e o caráter do homem como cidadão.

É notável que durante a história o homem tenha desenvolvido habilidades para conviver em sociedade que é resultante do seu trabalho, isto é, sua cultura (FREIRE, 2011c). Neste sentido, a valorização da cultura é um meio de estabelecer a continuidade e à sua historicidade, ao meio ao qual está integrado, isto é, a estruturação da sociedade ocorre na mesma intensidade em que são preservados os valores culturais desta sociedade. Nesta perspectiva, Kramer (1998, p. 22) ressalta que "a relevância simultânea das tradições culturais de cada grupo social, de seus 
valores, seu percurso, experiências, conhecimentos, acessos aos bens culturais disponíveis" podem beneficiar e propiciar o progresso pessoal de cada pessoa.

No seu interior a fonte essencial de inspirações filosóficas conduzem a saberes que possibilitam o aprendizado mais abrangente e os componentes culturais, ao serem propagados proporcionaram múltiplas influências que impulsionaram as pessoas através da história, assim, é bem preponderante tal fato, pois os processos históricosociais qualificam os moldes educacionais (REGO, 2014).

Por esta razão é imprescindível que sempre sejam observadas suas influências, considerando que produzem harmonia no processo de construção do conhecimento, pois para cada etapa histórica existiu um ensino, um conceito, motivo pelo qual é imprescindível o conhecimento dos alunos com todo seu contexto de vida, história, cultura, saberes visando desenvolver metodologias com significados próprios para cada aluno e contexto que está inserido e que seja baseado na cidadania e na dialogicidade.

Dessa forma, uma educação que possua por premissa básica os conhecimentos prévios do aluno, pode ser concebida como um processo fundamentado nos rigores das demandas atuais e que, concomitantemente, reconhece seu histórico e as especificidades de sua cultura, prestigiando sua identidade.

\section{A CULTURA E SUA INFLUÊNCIA NA EDUCAÇÃO}

A cultura de cada povo permeia todo processo educacional e como processo educativo tem previsão na legislação no art. 26, Lei 12.796/2013, modificando a Lei de Diretrizes e Bases da Educação Nacional (LDBEN, 9.394/96) situando-a como essencial e obrigatória, considerando-se que as ações educativas não podem dispensar que se reflita sobre o homem e seu contexto cultural (FREIRE, 2011b).

Dessa forma, Kramer (1998, p.16), explana que "a escola que estiver comprometida com a cidadania e democracia necessita ter essencialmente a constituição cultural, para que seja estabelecida uma cidadania integral e isso em razão de que o ensino- 
aprendizagem durante toda a história humana foi muito heterogêneo", isto é, somente o pensamento do professor era considerado e ignorados os dos alunos (REGO, 2014). Estes conhecimentos ressaltaram a importância de entender a dimensão que pode alcançar a cultura elaborada homogeneamente possibilitando aos indivíduos auferir mecanismos salutares de aceitar as próximas gerações, acompanhando o indivíduo durante sua vida inteira.

Assim, segundo Kramer (1998, p.22):

[...]. É fundamental que todos possam, tanto se apropriarem dos saberes científicos fundamentais, quanto aprenderem com todo seu histórico, seja nos livros, nos teatros, com as linguagens e as artes, seja no cinema, na música, na dança, considerando que a experiência nestes casos integra a formação cultural humanista imprescindíveis para o enfrentamento dos desafios mais potenciais da vida atual.

De acordo com Libâneo (2004, p. 61), "é premente que se considere, além de tudo, que os discentes vão para o ambiente escolar, trazendo suas significações, valores, crenças, formas de agir, que resultam de seus aprendizados informais, denominados como cultura paralela ou currículo extraescolar". Realmente estes são conhecimentos elaborados da experiência pessoal de cada pessoa interagindo com seu contexto, assim, estes darão a base de sustentação no momento de construir um pensamento ou um conceito da realidade (FREIRE, 2011b).

Entretanto, esta é uma vertente atual que evolui no século XX, onde a base que surge daí diz que a infância torna possível a evolução de um processo simbólico, que desenvolve a subjetividade baseando-se nos elementos culturais consolidados historicamente (SARMENTO, 2000).

Na concepção de Kramer (1998, p. 22), "a cultura brasileira no mundo da educação não é muito reconhecida na área, entretanto, constitui-se como um expressivo acervo teórico possibilitando ao educador se apropriar de uma metodologia baseada na cultura, em cada contexto onde estiver sendo desenvolvida". Assim, ela pode ser essencial em preencher as lacunas de aceitação dos valores diversificados do processo de socialização, fundado na transição entre a teoria e a prática da docência. 
Por conseguinte, pode ser auspicioso para a criança a utilização de elementos culturais, pois a auxilia a expandir sua forma de viver, seus relacionamentos com os demais, considerando que eles também são fascinados pelas manifestações culturais. Dessa forma, indubitavelmente a escola e a família são as principais responsáveis por transmitir e manter a cultura na sociedade, porém a maior dificuldade ainda é sistematizar esta cultura para transmiti-la de forma a não se valorizar mais os conteúdos que os temas culturais e do cotidiano a elas pertinentes, evitando os julgamentos e permitindo que os componentes culturais auxiliem na formação de melhores cidadãos conhecedores do contexto e que estão inseridos.

Neste sentido, a maior preocupação paira sobre se somente por meio da educação se pode assegurar a transmissão desta cultura, pois enquanto alguns educadores denotam indiferença às distinções de classe, outros querem extinguir completamente estas diferenças.

Outrossim, existe ainda o risco de compreender a "educação" de forma a englobar muito (quando requer que tudo o que importa preservar pode ser transmitido por ensino) ou bem pouco (quando requer que a educação deve se limitar ao que pode ser ensinado) (ELIOT, 1988).

Neste sentido, a organização pedagógica na escola deve atentar prioritariamente em sistematizar essa reprodução cultural como algo atrativo e que proporcione aprender uma nova forma de ver e compreender o mundo à sua volta. Tanto as crianças quanto os jovens estão convivendo com distintas representações culturais e existe uma contínua progressão no que se apresenta como cultura e a escola deve seguir o mesmo ritmo que as mídias estabelecem à nova cultura, pois elas atingem de forma bem mais rápida o público infanto-juvenil.

Entretanto, nas últimas duas décadas foram sendo elaboradas diversas áreas disciplinares, estudos culturais, etc. que usam noções e abordagens de métodos que propiciem a representação e compreensão de novas dificuldades até então implícitos na escola. Questões referentes aos jovens com criações e expressões de subjetividades (através da Internet, ou da sua forma de relacionar-se com a música e 
as imagens); com inovações nos valores estéticos e como se relacionam com a realidade (tais como os derivados da possibilidade para acessar, analisar, apropriar, transformar, criar, reproduzir as imagens, sons e estratégias de apresentação) (HERNÁNDEZ, 2009).

Devem ser observadas as formas de relação às quais os acessos não ocorrem somente mediante o passatempo, e também frente à imersão em indústrias culturais onde muitos jovens buscam e integram, mas que não são consideradas pelos docentes no seu planejamento, esquecendo-se que são responsáveis pelas políticas educativas; esferas que ficam excluídas do currículo ou que integram as classes de forma ocasional (HERNÁNDEZ, 2009).

Dessa forma, apesar de muitas vezes o aluno não consegue perceber o envolvimento cultural que o ambiente escolar promove (ou deveria promover) a ele e, por esta razão, não consegue correlacionar os conteúdos escolares com a cultura intrínseca ao seu próprio cotidiano. Compreenda-se que todos os âmbitos de convivência ou meros contatos culturais fazem que o homem construa novas referências desde sua infância nas primeiras impressões do mundo sendo balizada pelos processos educativos e isso ocorre por meio do contato com as mais distintas formas culturais que são elaboradas e reproduzidas se estendendo por toda sua existência.

\section{CONSIDERAÇÕES FINAIS}

Este estudo proporcionou o entendimento sobre o potencial de influência que a cultura exerce na educação, onde de um lado o aluno contribui com sua vivência no seu primeiro ambiente educacional que é sua família, com suas crenças e valores e do outro a educação como forma de sistematizar estes saberes através do desenvolvimento de diversos métodos como danças, teatros, cantos, dentre outros e tudo isso proporciona a compreensão do quanto são importantes as peculiaridades prévias dos alunos no processo ensino-aprendizagem.

Em uma análise mais aprofundada pode-se identificar o quanto são fundamentais os componentes culturais e artísticos para a evolução do ser humano desde a sua 
infância; pode-se ainda afirmar que eles são os fundamentos centrais na sua formação, possibilitando a aceitação nos mais distintos meios de pensamentos, de questionamentos e ações no mundo moderno, onde os conhecimentos são considerados supérfluos (esta perspectiva traz como consequência um mundo cada vez mais provisório).

Entretanto, toda proposta sociocultural deve ter como fundamento um cunho Vygostskyano, ou seja, fundamentado nas relações sociais originadas do meio em que está inserida. Este conhecimento se constrói por meio das interações familiares, nas rotinas vivenciadas e é essencial para seu crescimento.

Outrossim, os elementos culturais bem trabalhados proporcionam maior aceitação das diferenças que existem na sociedade, pois está se constitui a partir da miscigenação de distintos povos, onde cada peculiaridade cultural é muito importante a nível individual e social.

Assim, a cultura exerce forte influência na educação e, em suma, as concepções dos estudiosos da antropologia e dos educadores, mencionados no corpo deste estudo, é possível identificar que a cultura consiste em um processo de aquisição de conhecimentos de alta complexidade conferindo ao homem o potencial de exceder suas limitações partindo de suas experiências pessoais, implicando na diversidade cultural, de onde sua assimilação é critério de conhecimentos específicos, de responsabilidade da Educação e que, por conseguinte, é constituída de dialogicidade orientada para o desenvolvimento humano, e mediado com ferramentas culturais que tornem possível as experiências íntimas prementes à aquisição de tais conhecimentos.

Mediante este vínculo intrínseco entre Cultura e Educação, entende-se que é essencial que se exercite a reflexão-idealização, esta última demanda uma referência aos educadores e gestores culturais, que agenciam a cultura desde a infância. Por um lado o professor é o profissional que dialoga e o objetivo é desafiador em conhecer muito bem seu interlocutor, ao menos em referência às relações entre ensino e 
aprendizagem, pois auxiliar é tornar possível, fazer com..., portanto, dialogar e, para isso, é necessário o conhecimento sobre o que já existe, portanto, o diálogo.

Portanto, o diálogo é a essência da educação, onde o aluno direciona seu processo de aprendizagem direcionando as ações do professor e é o professor quem planeja e cria as formas de potencializar estes aprendizados (TACCA et al., 2005).

Em contrapartida desempenha ainda o papel de gestor cultural, onde, de posse da sensibilidade artística, conserva as habilidades dialógicas que o autorizam a se mover entre ambas as esferas e seu potencial mediador evidencia uma habilidade interdisciplinar.

\section{REFERENCIAS}

ALVES, Rubem. O que é científico. 9ª ed. São Paulo: Loyola, 2009.

BAMBERGER, Richard. Como incentivar o hábito de leitura. $7^{\mathfrak{a}}$ ed. São Paulo: Ática, 2002.

ELIOT, T. S. Notas para uma definição de cultura. Tradução: Eduardo Wolf. São Paulo: Realizações, 2012.

FREIRE, Paulo. A educação Como Prática da Liberdade. 34 ed. Rio de Janeiro: Paz e Terra, 2011a.

. Educação e mudança. 36ª ed. Rio de Janeiro: Paz e Terra, 2011b.

. Pedagogia do Oprimido. 45 $5^{\mathrm{a}}$ ed. Rio de Janeiro: Paz e Terra, 2011c.

A importância do ato de ler. $51^{\text {a }}$ ed. São Paulo: Cortez, 2017d.

FORQUIN, Jean Claude. Escola e Cultura: as bases sociais e epistemológicas do conhecimento escolar. Trad. Guacira Lopes Louro. Porto Alegre: Artes Medicas Sul, 1997. 
GIROUX, H. A. Praticando Estudos Culturais nas Faculdades de Educação. In: Silva, T. T. da. Alienígenas na Sala de aula. Petrópolis: Vozes, 2001. p. 85-103.

GUARESCHI, Pedrinho A. Sociologia Crítica: Alternativas de mudanças. $61^{a}$ ed. Porto Alegre: Mundo Jovem, 2008, p. 14-18.

HERNÀNDEZ, F. Catadores da Cultura Visual: Proposta para uma nova narrativa educacional. $2^{\underline{a}}$ ed. Porto Alegre: Mediação, 2009.

KUENZER, Acácia Zeneida. Conhecimento e competências no trabalho e na escola. Boletim técnico do SENAC, Rio de Janeiro, v. 28, n. 2, p. 03-11, 2002.

LIBANÊO, José Carlos. Organização e gestão da escola: teoria e prática. 6ª ed. São Paulo: Alternativa, 2013.

LOPES, Karina Rizek; MENDES, Roseana Pereira; FARIA, Vitória Líbia Barreto de (Orgs.). Coleção pro-infantil modulo Il unidade 3 livros de estudo. vol. 2. Brasília: MEC. 2005. Disponível em: http://portal.mec.gov.br/seb/arquivos/pdf/Educinf/mod_ii_vol2unid2.pdf Acesso em: 10/09/2019.

MORIN, Edgar. A cabeça bem-feita: repensar a reforma, reformar o pensamento. $21^{\text {a }}$ edição. Rio de Janeiro: Bertrand Brasil, 2014.

OLIVEIRA, Pérsio Santos de. Introdução à sociologia. 30ª ed. São Paulo: Ática, 2011. PIMENTEL, Alessandra. A ludicidade na educação infantil: uma abordagem históricocultural. Psicologia da educação, n. 26, p. 109-133, 2008.

REGO, Teresa Cristina. Vygotsky: uma pesquisa histórico-cultural da educação. 25a ed. Petrópolis: Vozes, 2014.

SARMENTO, Manuel Jacinto. As lógicas de ação nas escolas. Lisboa: Instituto de Inovação Educacional, Ministério da Educação, 2000. 
SEVERINO, Antônio Joaquim. Filosofia da educação: construindo a cidadania. São Paulo: FTD, 2010.

TACCA, M.C.V.R; TUNES, E.; BARTHOLO Jr., R. O professor e o ato de ensinar.

In Cadernos de Pesquisa, v. 35, n. 126, p. 689-698, set./dez. 2005. Disponível em:http://www.scielo.br/pdf/cp/v35n126/a08n126.pdf Acesso em: 10/09/2019.

VYGOTSKY, L. S. A formação social da mente. $7^{\text {a }}$ ed. Rio de Janeiro: Martins Fontes,2007.

Enviado: Setembro, 2019.

Aprovado: Outubro, 2019. 